\title{
Comparison of Clinical and Radiological Outcomes of Cemented, Uncemented, and Hybrid Total Hip Arthroplasties
}

Izzet KORKMAZ1', Olgun BINGOL ${ }^{1}$, Guzelali OZDEMIR', Enver KILIC ${ }^{1}$, Mahmut Nedim AYTEKIN²

${ }^{1}$ Ankara City Hospital, Orthopaedics and Traumatology Clinic, Cankaya, Ankara, Turkey

${ }^{3}$ Ankara Yıldırım Beyazıt University, Faculty of Medicine, Orthopaedics and Traumatology, Cankaya, Ankara, Turkey

Correspondence

Izzet KORKMAZ

Ankara Şehir Hastanesi, Ortopedi ve Travmatoloji Kliniği, Ankara, Türkiye

e-mail:korkmazmail@yahoo.com

\section{ABSTRACT}

This study aimed to compare the clinical and radiological outcomes of cemented, uncemented, and hybrid total hip arthroplasty (THA) applications.

The study was designed as a single-center and retrospective trial. Patients who underwent THA between April 1995 and December 2001 at the Tepecik Training and Research Hospital in Izmir, Turkey, were included in the study. The outcomes of 23 THAs of 21 patients [7 cemented THAs (cTHAs), 8 uncemented THAs (uTHAs), and 8 hybrid THAs (hybrid THAs)] were assessed. The participants were clinically and radiologically evaluated.

The mean age of the participants was 56.4 years (range: $22-73$ ). The mean follow-up duration was 39 months. The radiological evaluation revealed radiolucent lines around the femoral components of 4 cTHA patients and the acetabular components of 3 cTHA patients. However, none of the participants developed clinical loosening. Seventy-five percent of uTHA patients had excellent Harris hip score results, whereas this rate was $57.1 \%$ for cTHA patients and $62.5 \%$ for hybrid THA patients.

The assessment of all three methods of THA indicated that the uTHA method had superior outcomes.

Key words: Cemented, hybrid, radiological evaluation, total hip arthroplasty, uncemented

\section{INTRODUCTION}

Total hip arthroplasty (THA) is one of the most common orthopedic surgeries (1). Pioneered by Sir John Charnley, THA has become a widely accepted surgical practice owing to advances in design and metallurgy, a better understanding of biology, and novel surgical techniques.

The initial cemented THA prosthetic applications were associated with problems such as intraoperative hypotension, sudden death, aseptic loosening, and periprosthetic bone loss in young patients $(2,3)$. This has led researchers to seek new designs, and uncemented prosthetics are widely preferred (4). Both cemented and uncemented designs have their own sets of advantages and disadvantages.

This study aimed to compare the clinical and radiological outcomes of cemented, uncemented, and hybrid THA applications.

\section{MATERIAL AND METHODS}

The study was designed as a single-center and retrospective trial. Patients who underwent THA between April 1995 and December 2001 at the Tepecik Training and Research Hospital were included in the study. All the researchers who participated in the study signed the most recent version of the Helsinki Declaration. The informed consent form was obtained from the patients in the study.

During the indicated time frame, 53 total hip arthroplasties were performed in the center on 48 patients. Patients followed up for at least 2 years were included in this study. Seven of the surgical patients opted out of follow-up, while 20 patients were excluded from the study due to insufficient follow-up time. Therefore, 23 total hip arthroplasties of 21 patients were evaluated in the study. 


\section{Surgical procedure}

All surgical procedures were performed by the same senior author. All patients were operated on in the lateral decubitus position using the approach described by Osborne. For the 23 hips included in the study, 7 cemented total hip arthroplasties (cTHA), 8 uncemented total hip arthroplasties (UTHA), and 8 hybrid (uncemented acetabular component and cemented femoral component) total hip arthroplasties (hybrid THA) were applied. The Link hip prosthesis (Hamburg, Germany) was used for all patients included in the study.

\section{Postoperative follow-up}

The surgical wound was assessed and dressed during the postoperative follow-up. A first-generation cephalosporin was administered for $24 \mathrm{~h}$ for postoperative antibiotic prophylaxis. Low-molecular-weight heparin was used for 35 days for deep vein thrombosis prophylaxis. Surgical stitches were removed after 2 weeks. Indomethacin prophylaxis was given for 15 days to prevent postoperative ectopic bone formation.

All participants were evaluated by the same senior author using the Harris hip score (HHS) (5) in postoperative week 6; in postoperative months 3,6 , and 12; and every year after that.

The loosening was radiologically assessed according to the three acetabular zones described by DeLee and Charnley (6) and the seven femoral zones described by Gruen (7) using anteroposterior pelvis and hip radiographs. The patients were also assessed for component position and migration, remodeling of the femur, and ectopic bone formation. Migration was calculated using the criteria suggested by Callaghan et al. (8). Ectopic bone formation was evaluated using the classification method described by Brooker et al. (9). Radiolucency of $\geq 2 \mathrm{~mm}$ in the described zones was evaluated as the criterion for radiological loosening.

\section{Statistical analysis}

The minimum, maximum, and average values of the data from the study were evaluated using Microsoft Excel.

\section{RESULTS}

Twenty-one patients were included in the study. A total of 23 total hip arthroplasties were evaluated. The mean age of the participants was 56.4 years (range: 22-73). The age distribution of the participants is presented in Figure 1. The demographic characteristics of the participants are summarized in Table 1. The etiology distribution of the participants is presented in Figure 2.

The preoperative HHS values of all participants were less than 60. Among the four CTHA patients who completed 5 years of follow-up, two had excellent and two had good HHS results. Two CTHA patients who completed 3 years of follow-up had excellent HHS results, and 1 CTHA patient who completed 2 years of follow-up had a good HHS result. For the UTHA patients, two had good and six had excellent hip scores at the last follow-up. The HHS results of the hybrid THA patients are summarized in Figure 3 and Table 2.

None of the participants developed clinical loosening during the follow-up period.

According to the acetabular zones described by DeLee and Charnley (6), two cTHA patients developed radiolucent lines in zone I and one in zones I and III. None of these patients had acetabular discontinuity. No signs of cement fracture or failure in the acetabular components of the seven CTHA patients were observed. Vertical or horizontal migration or erosion of

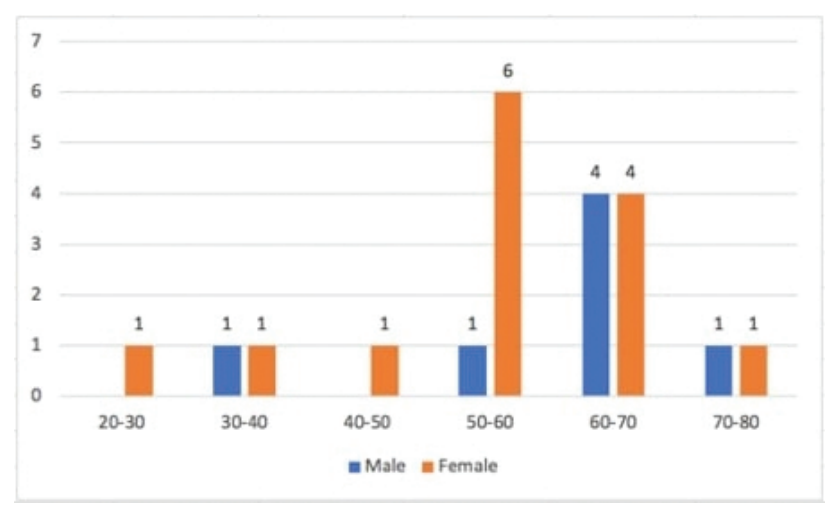

Figure 1 Distribution of age.

Table 1 Demographic data

\begin{tabular}{ll}
\hline Age (year) & 56.4 (min: 22; max: 73) \\
Sex (female/male) & $13 / 8$ \\
Side (Right/Left) & $9 / 14$ \\
Follow-up time (month) & $39(\min : 24, \max : 60)$ \\
\hline
\end{tabular}




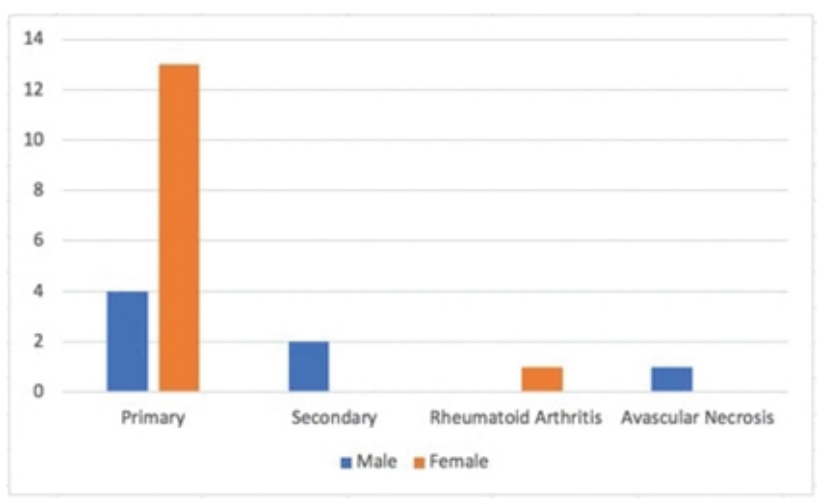

Figure 2 Distribution of patients according to etiology.

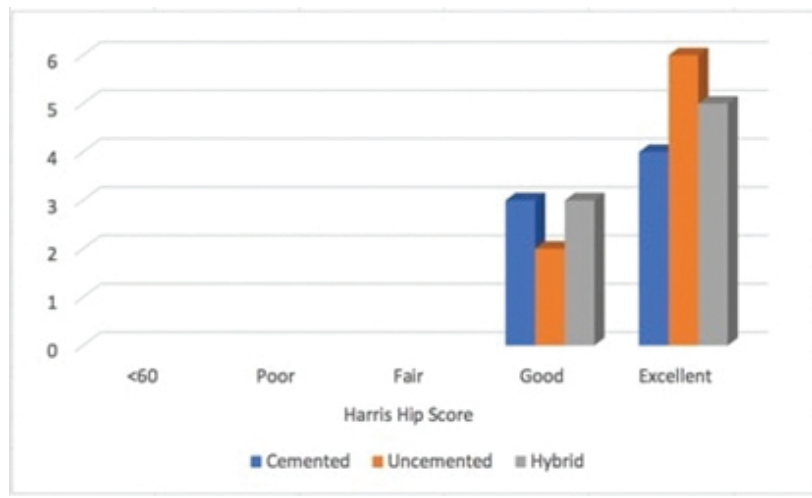

Figure 3 Harris hip score at the last control of the patients.

Table 2 Demographic data

\begin{tabular}{ll}
\hline & Harris hip score \\
Cemented system & Excellent: $4(57.1 \%)$ \\
& Good: $3(42.9 \%)$ \\
Uncemented system & Excellent: 6 (75\%) \\
& Good: $2(25 \%)$ \\
Hybrid system & Excellent: $5(62.5 \%)$ \\
& Good: $3(37.5 \%)$ \\
\hline
\end{tabular}

the acetabular component was not observed in any of the 23 total hip arthroplasties.

The evaluation of the femoral components of all participants revealed radiolucent lines, not exceeding $1 \mathrm{~mm}$, in zone I in four CTHA patients and zones I and III in one CTHA patient. When the position of the femoral component was evaluated, it was observed that the femoral component was in varus malposition in 2 hips, in valgus malposition in 1 hip, and neutral in 20 hips. Further, it was observed that the component

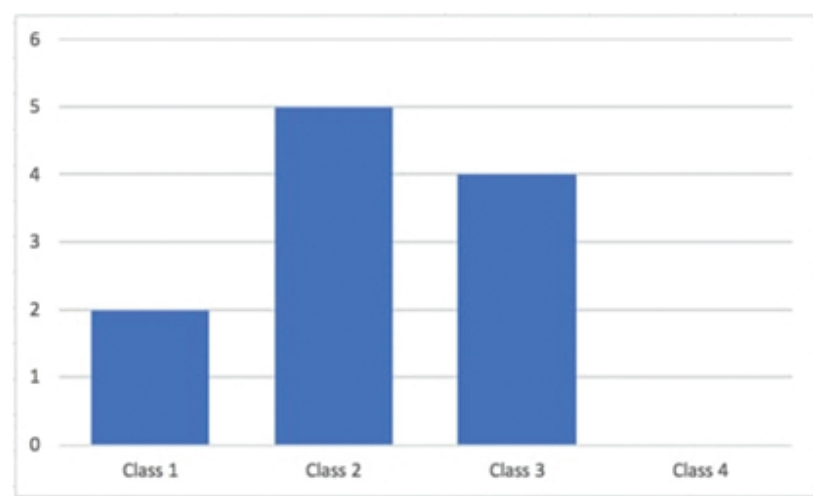

Figure 4 Ectopic bone formation of patients.

was not placed in a neutral position in patients with radiolucencies in the femoral component. None of the patients developed vertical femoral component collapse.

Seventeen of the hip arthroplasties evaluated in the study developed various complications. Two patients developed superficial infections and were treated with antibiotics. Three patients developed deep vein thrombosis as detected by venous Doppler ultrasonography. However, these patients did not show any signs of pulmonary embolism. Eleven patients developed ectopic bone formation. Two of these patients were Brooker Class 1, five were Class 2, and four were Class 3 (Figure 4). However, the functional capacities of these patients were not negatively affected. One patient developed a leg length discrepancy of $1.5 \mathrm{~cm}$ after the surgery.

\section{DISCUSSION}

The most important finding of this study was that the moderate-term clinical and radiological outcomes of UTHA patients were superior to those of CTHA and hybrid THA patients.

The orthopedics literature mentions important advantages of cemented prostheses such as superior initial stability; significant pain relief; reduced metal methacrylate use in implants, which reduces ion release; limited oncogenic effect; and good long-term results $(1,10,11)$. However, they are also associated with problems such as intraoperative hypotension, sudden death, aseptic loosening of the acetabular component, and periprosthetic bone loss in young and active patients $(2,3)$. This has led researchers to seek new designs, and uncemented prosthetics is 
widely preferred (4). Recent studies have introduced hybrid systems for total hip prostheses where the acetabular component is uncemented and the femoral component is cemented $(1,11)$. This study aimed to compare the moderate-term outcomes of all three methods of total hip replacement performed in the clinic.

The literature mentions that the HHS values range from 89 to 95 in the long-term follow-ups of CTHA and uTHA patients (11-13). The results of this study were consistent with the literature.

Further, $1.5 \%-16 \%$ of UTHA patients develop anterior thigh pain $(14,15)$. The thigh pain is more common with large intramedullary stems and reduced with small stems wide in the proximal region and narrow toward the distal region (16). In this study, none of the patients who underwent UTHA developed anterior thigh pain. This low prevalence might be associated with the limited number of patients who underwent UTHA and application of an appropriate femoral component compatible with the proximal femur using an adequate technique.

None of the participants developed the clinical signs of loosening. This finding was consistent with the literature regarding the long-term follow-up of cemented systems and the moderate-term follow-up of uncemented systems (17-20).

The incidence of radiolucent lines around the acetabular cup was reported to be $12.2 \%-40 \%$ for THA patients (21-24). In this study, $13 \%$ of the participants (three patients) developed radiolucency. Also, the acetabular inclination was not found to be associated with radiolucency. Radiolucency was not observed in femoral components in a neutral position.

Stress shielding is another complication associated with femoral stems in patients followed up for THA $(25,26)$. Callaghan et al. reported that $70 \%$ of the patients in their study developed stress shielding (27). In this study, stress shielding was observed in $43.4 \%$ of the participants.

The literature indicates the incidence of ectopic bone formation after THA to be between $0.6 \%$ and $90 \%(28,29)$. In this study, 11 patients $(47 \%)$ developed ectopic bone formation. The reason behind this complication is not yet clearly understood. However, it is reported to occur after excessive bone resection or severe soft tissue trauma (30). The risk of heterotopic ossification is higher for transtrochanteric, anterolateral, and lateral interventions compared with posterolateral interventions (31). In this study, the posterolateral approach was used, and no loss of function resulting from ectopic bone formation was observed.

Infection is one of the most important complications of THA (32). The literature reports that prophylactic antibiotic therapy, duration of the surgery, flow systems used in operating rooms, and graft use affect infection rates (33). The rate of infection is reported to be $1 \%-2 \%$ after THAs $(32,34)$. In this study, none of the participants developed deep infections nor required revision due to infection. Only two patients (8.6\%) developed superficial infections.

Dislocation is reported to be one of the complications of THA most commonly requiring revision surgeries (35). Studies reported the incidence of dislocation after THA to be between $0.2 \%$ and $10 \%$ (36). In this study, none of the patients developed dislocations. This might be associated with the proper placement of the acetabular and femoral components, careful rehabilitation, and effective patient-physician cooperation.

The limitations of this study were the use of retrospective data from a single center and the small number of patients. The strength of the study was the comparison performed using three different methods in a single study.

\section{CONCLUSIONS}

While evaluating all three methods of THA, this study found that the UTHA method had superior outcomes. However, longer-term results evaluating all three systems are needed. We believe that the moderate-term follow-up results of the study may help shed light on the evaluation of future long-term follow-ups.

\section{ACKNOWLEDGMENTS}

The authors received no financial support for the research and/or authorship of this manuscript. The authors declared no conflicts of interest with respect to the authorship and/or publication of the manuscript. All the authors have read and approved the manuscript. 
We wish Allah's mercy to our valuable teacher, Late Rıfkı US, who contributed significantly to this study.

\section{REFERENCES}

1. Phedy P, Ismail HD, Hoo C, Djaja YP. Total hip replacement: $A$ meta-analysis to evaluate survival of cemented, cementless and hybrid implants. World J Orthop. 2017;8(2):192.

2. Scott CEH, MacDonald D, Moran M, White TO, Patton JT, Keating JF. Cemented total hip arthroplasty following acetabular fracture. Bone Joint J. 2017;99(10):1399-408.

3. Sandiford NA, Jameson SS, Wilson MJ, Hubble MJW, Timperley AJ, Howell JR. Cement-in-cement femoral component revision in the multiply revised total hip arthroplasty: results with a minimum follow-up of five years. Bone Joint J. 2017;99(2):199 203.

4. Slaven SE, Purcell RL, Mack AW, Bedard NA, Warth LC, Callaghan JJ. Results of porous-coated anatomic total hip arthroplasty without cement at 25 to 30 years: a concise follow-up of a previous report. JBJS. 2017;99(19):1647-53.

5. Söderman $P, M a l c h a u H$. Is the Harris hip score system useful to study the outcome of total hip replacement? Clin Orthop Relat Res. 2001;384:189-97.

6. DeLee JG, Charnley J. Radiological demarcation of cemented sockets in total hip replacement. Clin Orthop Relat Res. 1976;(121):20-32.

7. Gruen TA, McNeice GM, Amstutz HC. "Modes of failure" of cemented stem-type femoral components: a radiographic analysis of loosening. Clin Orthop Relat Res. 1979 Jun;(141):1727.

8. Callaghan JJ, Salvati EA, Pellicci PM, Wilson PDJ, Ranawat CS Results of revision for mechanical failure after cemented total hip replacement, 1979 to 1982 . A two to five-year follow-up. J Bone Joint Surg Am. 1985 Sep;67(7):1074-85.

9. Brooker AF, Bowerman JW, Robinson RA, Riley LHJ. Ectopic ossification following total hip replacement. Incidence and a method of classification. J Bone Joint Surg Am. 1973 Dec;55(8):1629-32.

10. Costi K, Solomon LB, McGee MA, Rickman MS, Howie DW. Advantages in using cemented polished tapered stems when performing total hip arthroplasty in very young patients. J Arthroplasty. 2017;32(4):1227-33.

11. Johnston RC, Fitzgerald RHJ, Harris $W H$, Poss R, Muller $M E$, Sledge CB. Clinical and radiographic evaluation of total hip replacement. A standard system of terminology for reporting results. J Bone Joint Surg Am. 1990 Feb;72(2):161-8.

12. Singh JA, Schleck C, Harmsen S, Lewallen D. Clinically important improvement thresholds for Harris Hip Score and its ability to predict revision risk after primary total hip arthroplasty. BMC Musculoskelet Disord. 2016;17(1):256.

13. Galea VP, Florissi I, Rojanasopondist P, Connelly JW, Ingelsrud LH, Bragdon C, et al. The Patient Acceptable Symptom State for the Harris Hip Score Following Total Hip Arthroplasty: Validated Thresholds at 3-Month, 1-, 3-, 5-, and 7-Year Follow-Up. J Arthroplasty. 2020;35(1):145-52

14. Jo W-L, Lee Y-K, Ha Y-C, Park M-S, Lyu S-H, Koo K-H. Frequency, developing time, intensity, duration, and functional score of thigh pain after cementless total hip arthroplasty. J Arthroplasty. 2016;31(6):1279-82.

15. Byrick RJ, Bell RS, Kay JC, Waddell JP, Mullen JB. High-volume, high-pressure pulsatile lavage during cemented arthroplasty. J Bone Joint Surg Am. 1989 Oct;71(9):1331-6.
16. Baert IAC, Lluch E, Van Glabbeek F, Nuyts R, Rufai S, Tuynman J, et al. Short stem total hip arthroplasty: potential explanations for persistent post-surgical thigh pain. Med Hypotheses. 2017;107:45-50.

17. Mulroy Jr RD, Harris WH. The effect of improved cementing techniques on component loosening in total hip replacement. An 11-year radiographic review. J Bone Joint Surg Br. 1990;72(5):757-60.

18. Hukkanen M, Corbett SA, Batten J, Konttinen YT, McCarthy ID, Maclouf J, et al. Aseptic loosening of total hip replacement. J BONE Jt SURGERY-AMERICAN Vol. 1997;79:467-74.

19. Havelin LI, Espehaug B, Vollset SE, Engesaeter LB. Early aseptic loosening of uncemented femoral components in primary total hip replacement. A review based on the Norwegian Arthroplasty Register. J Bone Joint Surg Br. 1995;77(1):11-7.

20. Haddad FS, Cobb AG, Bentley G, Levell NJ, Dowd PM. Hypersensitivity in aseptic loosening of total hip replacements: the role of constituents of bone cement. J Bone Joint Surg Br. 1996;78(4):546-9.

21. Imai H, Miyawaki J, Kamada T, Maruishi A, Takeba J, Miura H. Radiolucency around highly porous sockets and hydroxyapatite-coated porous sockets in total hip arthroplasty for hip dysplasia. Eur J Orthop Surg Traumatol. 2019;29(3):6118.

22. Carli A V, Warth LC, de Mesy Bentley KL, Nestor BJ. Short to midterm follow-up of the tritanium primary acetabular component: a cause for concern. J Arthroplasty. 2017;32(2):4639.

23. Faizan A, Chuang $P$, Aponte C, Moretti V, Sharkey PF. Radiolucencies surrounding acetabular components with three-dimensional coatings: artifact or real? Arthroplast today. 2017;3(4):269-74.

24. Matuszak SJ, Galea VP, Connelly JW, Christiansen J, Muratoglu O, Malchau H. Periprosthetic acetabular radiolucency progression in mid-term follow-up of the articular surface replacement hip system. Arch Orthop Trauma Surg. 2018;138(7):1021-8.

25. Kawaji H, Uematsu T, Oba R, Hoshikawa N, Watanabe H, Takai $\mathrm{S}$. Influence of femoral implant alignment in uncemented total hip replacement arthroplasty: varus insertion and stress shielding. J Nippon Med Sch. 2016;83(6):223-7.

26. Sanli I, Arts JJC, Geurts J. Clinical and radiologic outcomes of a fully hydroxyapatite-coated femoral revision stem: excessive stress shielding incidence and its consequences. J Arthroplasty. 2016;31(1):209-14.

27. Callaghan JJ, Dysart SH, Savory CG. The uncemented porouscoated anatomic total hip prosthesis. Two-year results of a prospective consecutive series. J Bone Joint Surg Am. 1988 Mar;70(3):337-46.

28. White PB, Ramkumar PN, Meftah M, Ghazi N, Ranawat AS, Ranawat CS. Incidence of heterotopic ossification following a multimodal pain protocol in total hip arthroplasty with the posterior approach. Orthopedics. 2018;41(1):e92-7.

29. DeBaun M, Ziino C, LaPrade C, Pun S, Avedian R, Bellino M. An anatomic classification for heterotopic ossification about the hip. J Orthop. 2020;

30. Park C, Merchant I. Complications of Total Hip Replacement. In: Total Hip Replacement-An Overview. IntechOpen; 2018.

31. Morrey BF, Adams RA, Cabanela ME. Comparison of heterotopic bone after anterolateral, transtrochanteric, and posterior approaches for total hip arthroplasty. Clin Orthop Relat Res. 1984;(188):160-7.

32. Pulido L, Ghanem E, Joshi A, Purtill JJ, Parvizi J. Periprosthetic joint infection: the incidence, timing, and predisposing factors. Clin Orthop Relat Res. 2008 Jul;466(7):1710-5. 
33. Parvizi J, Shohat N, Gehrke T. Prevention of periprosthetic joint infection: new guidelines. Bone Joint J. 2017;99(4 Supple_B):3-10.

34. Springer BD, Cahue S, Etkin CD, Lewallen DG, McGrory BJ. Infection burden in total hip and knee arthroplasties: an international registry-based perspective. Arthroplast today. 2017;3(2):137-40.

35. Addona JL, Gu A, De Martino I, Malahias M-A, Sculco TP,
Sculco PK. High Rate of Early Intraprosthetic Dislocations of Dual Mobility Implants: A Single Surgeon Series of Primary and Revision Total Hip Replacements. J Arthroplasty. 2019;34(11):2793-8.

36. Dargel J, Oppermann J, Brüggemann G-P, Eysel P. Dislocation following total hip replacement. Dtsch Arztebl Int. 2014;111(51-52):884. 